\title{
频哪醇硼烷在酮及亚胺的不对称嗍氢化中的应用
}

\author{
刘文伯陆展* \\ (浙江大学化学系 杭州 310000)
}

\begin{abstract}
摘要 手性醇及手性胺化合物被广泛应用于有机合成、材料科学、医药、农用化学及精细化工，酮及亚胺的不对称硼 氢化反应为制备该类化合物提供了有效手段. 频哪醇硼烷，自 1991 年被报道以来，作为一种稳定的、商品化的、易定 量的有机硼试剂被广泛应用于羰基化合物、亚胺及腈类化合物的还原反应及其机理研究中. 在过去 5 年里, 频哪醇硼 烷也被应用于不对称嗍氢化反应，以制备手性醇及手性胺. 按不同的催化剂，如地球丰产过渡金属、主族元素及稀土金 属分类, 介绍频哪醇嗍烷参与的酮和亚胺的不对称催化硼氢化反应.
\end{abstract}

关键词 频哪醇嗍烷; 不对称硼氢化; 廉价金属; 酮; 亚胺

\section{Application of Pinacolborane in Catalytic Enantioselective Hydroboration of Ketones and Imines}

\author{
Liu, Wenbo Lu, Zhan* \\ (Department of Chemistry, Zhejiang University, Hangzhou 310000)
}

\begin{abstract}
Enantioselective hydroboration of ketones and imines provides a powerful method to access valuable chiral alcohols and amines which are widely used in organic synthesis, materials science, pharmaceutical, agrochemistry and fine chemical industry. After invented in 1991, pinacolborane (HBpin) as a stable, commercially available and measurably simple reductive reagent has been widely applied in hydroboration of carbonyl derivatives, imines and nitriles and relevant mechanistic investigation. In the past 5 years, HBpin has also been employed for asymmetric catalytic hydroboration (CHB) to access chiral alcohols and amines. The enantioselective CHB reactions of ketones and imines using HBpin are outlined according to the classification of different catalysts, such as earth abundant transition metals, main group elements, and rare-earth metals.
\end{abstract}

Keywords pinacolborane; asymmetric hydroboration; earth abundant transition metal; ketone; imine

\section{Introduction}

Hydroboration of unsaturated compounds, such as like alkenes, allenes and alkynes, is one of the most powerful and straightforward methods to access various organoboranes which serve as versatile synthetic intermediates and reagents in lots of important organic transformation. ${ }^{[1]}$ Meanwhile, hydroboration of polarized multiple bond in carbonyl derivatives, imines and nitriles with organoboranes or metal borohydrides provides a powerful way to build valuable alcohols and amines. ${ }^{[2]}$ The rapid reduction of carbonyl group with diborane has been known for a long time. ${ }^{[3]}$ For the low cost, operable and storage simplicity, and divergent chemical selectivity, a variety of boranes with different structures have been synthesized for applications (Scheme 1) ${ }^{[4]}$ Especially, in terms of stereoselectivity and diastereoselectivity, the chiral boranes derived from natural available chiral alkenes such as $\alpha$-pinene and amino acids play an important role as reductants ${ }^{[4]}$ or catalysts ${ }^{[5]}$ in asymmetric synthesis.

HBpin is a kind of commercially available reductant, which was first synthesized by Knochel et al. ${ }^{[6]}$ in 1992 as a new hydroboration reagent for alkenes and alkynes. During the past 3 decades, catalytic hydroboration $(\mathrm{CHB})$ reactions with HBpin have been explored for both applications and mechanistic investigations. ${ }^{[2,7]}$ In 2009, HBpin was first used in CHB of carbonyls and imines by Casey and Clark et al. ${ }^{[8]}$ A boron-substituted analogue of the Shvo's

\footnotetext{
* Corresponding author. E-mail: luzhan@zju.edu.cn

Received August 21, 2020; revised September 8, 2020; published online September 15, 2020.

Dedicated to the 40th anniversary of Chinese Journal of Organic Chemistry

Project supported by the National Natural Science Foundation of China (Nos. 21922107, 21772171), the Natural Science Foundation of Zhejiang Province (No. LR19B020001), the Center of Chemistry for Frontier Technologies and the Fundamental Research Funds for the Central Universities (No. 2019QNA3008). 国家自然科学基金(Nos. 21922107, 21772771)、浙江省自然科学基金(No. LR19B020001)、浙江大学化学前瞻技术研究中心和中央高校基本科研业务 费(No. 2019QNA3008)资助项目.
} 


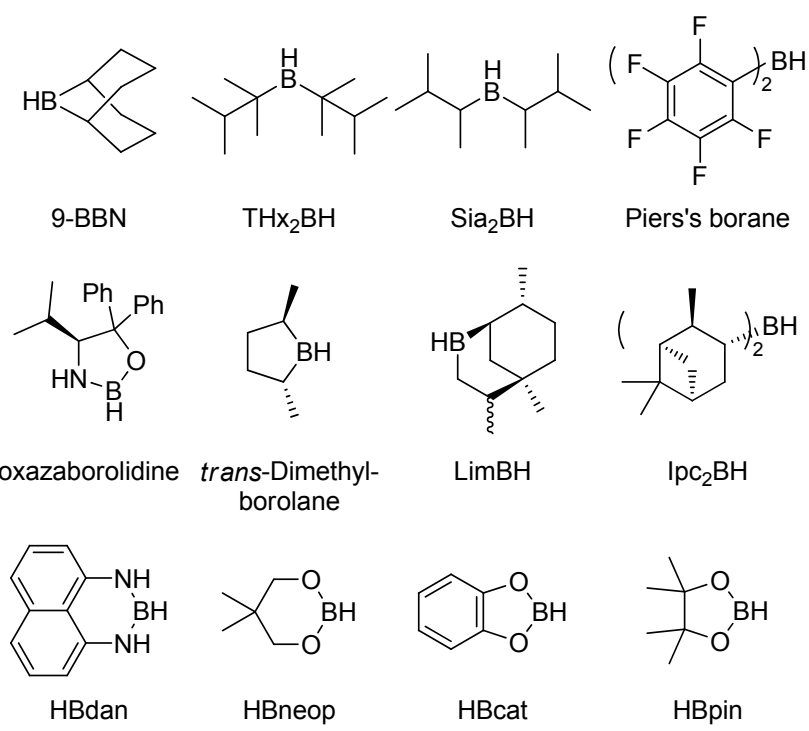

Scheme 1 Selected examples of boranes

catalyst was synthesized and used as catalyst. The simple Lewis base such as $\mathrm{NaO}^{t} \mathrm{Bu}^{[9]}$ and $\mathrm{NaOH}^{[10]}$ was also found capable of catalyzing hydroboration of carbonyl with HBpin. It was not until 2015 that the enantioselective CHB of ketones with HBpin was first established by our group with OIP- $\mathrm{CoCl}_{2}$ complex. ${ }^{[11]}$ Then, various catalysts have been explored with the combination of HBpin by other research groups, and the enantioselective $\mathrm{CHB}$ of imines with HBpin was also achieved by Speed et al. ${ }^{[12]}$

This review summarizes the enantioselective hydroboration of ketones and imines with HBpin to access chiral alcohols and amines, and classifies them according to different catalysts such as earth abundant transition metals, main group elements, and rare earth metals.

\section{Catalytic enantioselective hydrobora- tion of ketones and imines with Hbpin}

\subsection{Earth abundant transition metals catalysis}

Traditional enantioselective hydrogenation of ketones catalyzed by noble metals provides a highly efficient and atom-economic method to produce chiral secondary alcohols with high $e e^{[13]}$ As CHB provides a useful alternative with mild and safe conditions and simple operation, CHB systems of ketones and imines catalyzed by earth abundant transition metals have been gaining interest.

The use of HBpin for enantioselective hydroboration of ketones was first established by our group in 2015 using OIP- $\mathrm{CoCl}_{2}$ complex (Scheme 2). ${ }^{[11]} \mathrm{A}$ wide range of alkyl aryl ketones were converted into secondary alcohols with high optical purity under mild conditions. This manner can be scale up to gram-scale without loss in enantioselectivity. In 2020, this Co-catalyzed reaction was also applied into enantioselective hydroboration of asymmetric diaryl ketones using IIP-CoCl${ }_{2}$ complex with HBpin (Scheme 3). ${ }^{[14]}$ A series of diaryl and aryl heteroaryl methanols were constructed with good to excellent yield and $e e$.

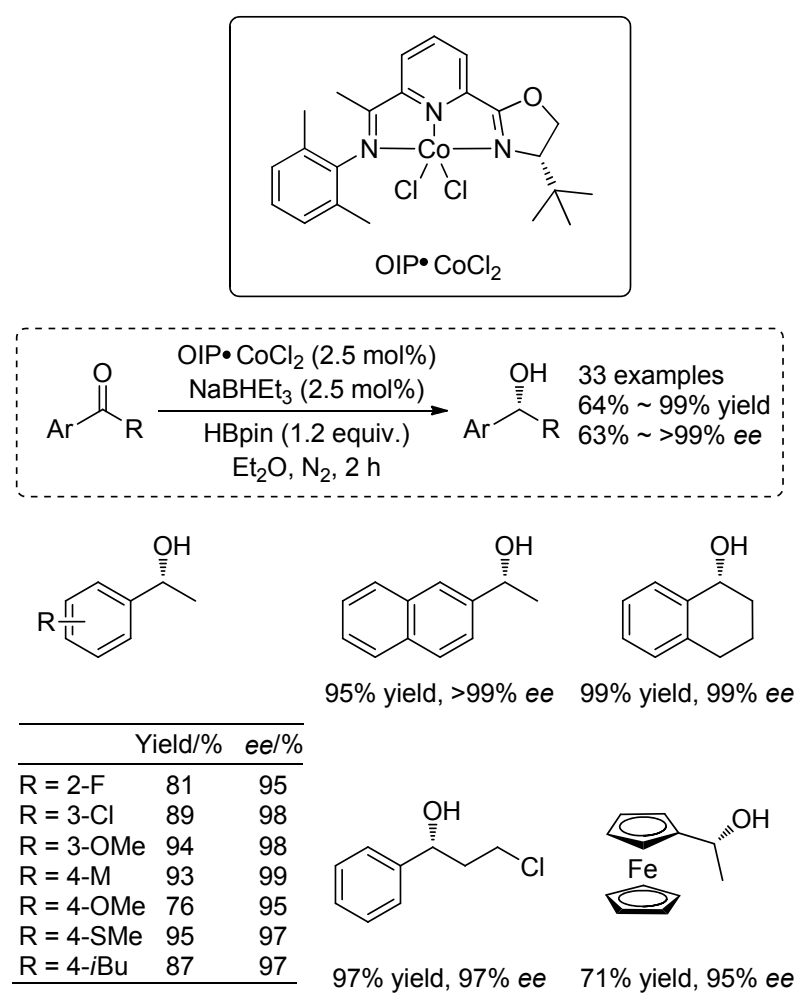

Scheme 2 Cobalt-catalyzed enantioselective hydroboration of ketones by $\mathrm{Lu}$
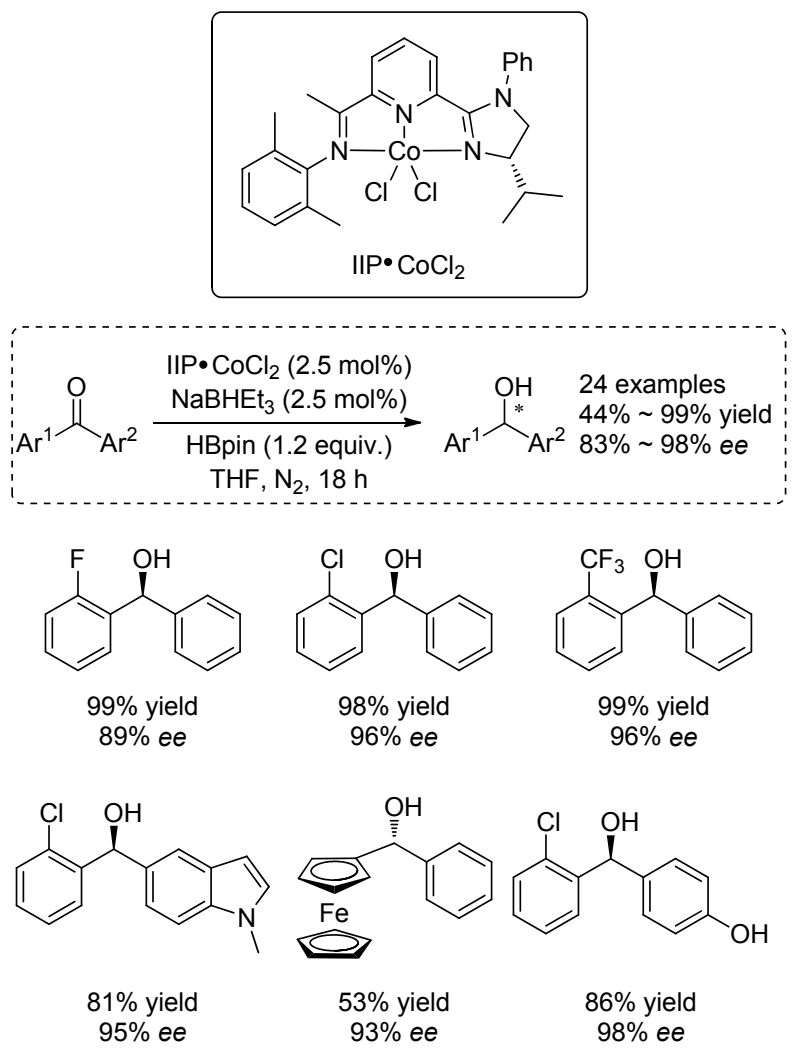

Scheme 3 Cobalt-catalyzed enantioselective hydroboration of diaryl ketones by $\mathrm{Lu}$

In 2017, Zhu et al. ${ }^{[15]}$ employed NiH/Pmrox-catalyzed 
system on enantioselective 1,2-hydroboration of $\alpha, \beta$-unsaturated ketones (Scheme 4). Broad functional group and high level of enantioselectivity and ambidoselectivity for 1,2- over 1,4-reduction were shown in this protocol. The addition of 1,4-diazabicyclo[2.2.2] octane (DABCO) was necessary for excellent regioselectivity and enantioselective.

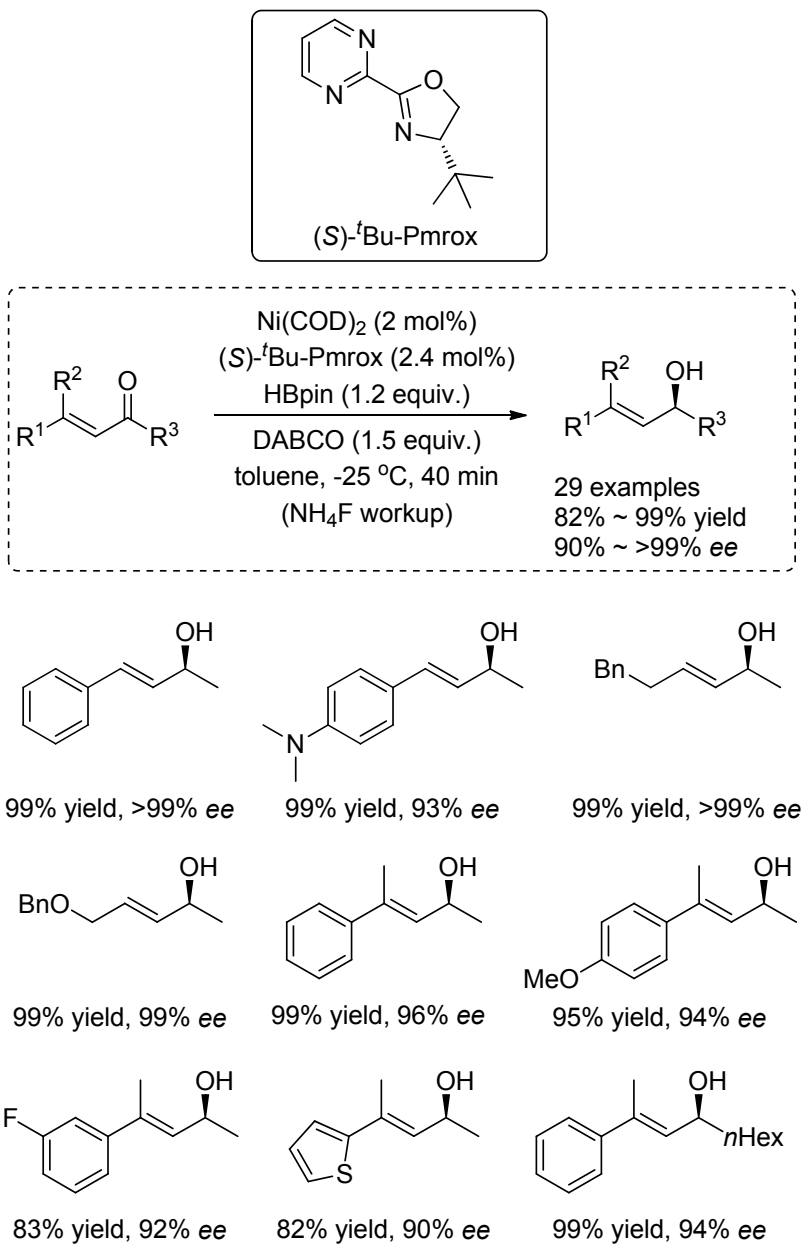

Scheme 4 Nickel-catalyzed enantioselective hydroboration of $\alpha, \beta$-unsaturated ketones by Zhu

In 2017, Gade et al. ${ }^{[16]}$ reported enantioselective hydroboration of ketones using boxmi manganese alkyl complex as a catalyst (Scheme 5). A series of alkyl aryl ketones were reduced by HBpin with $80 \% \sim>99 \%$ ee. Replacement of $\mathrm{HBpin}$ with $\mathrm{HBcat}, \mathrm{BH}_{3}$-THF or 9-BBN gave $0 \sim 10 \%$ ee.

In 2018, a thorough mechanistic investigation was conducted by Gade's group ${ }^{[17]}$ on the previously reported hydroboration system based on boxmi manganese alkyl complex (Scheme 6). Two productive cycles were proposed and supported by Hammett correlations, KIE measurements, Eyring analysis and density functional theory (DFT) model. The main path involved was a boraneassisted, combined insertion/alkoxide release process. This cycle could proceed in the absence of manganese hydride. Because of dependence on concentration of HBpin and

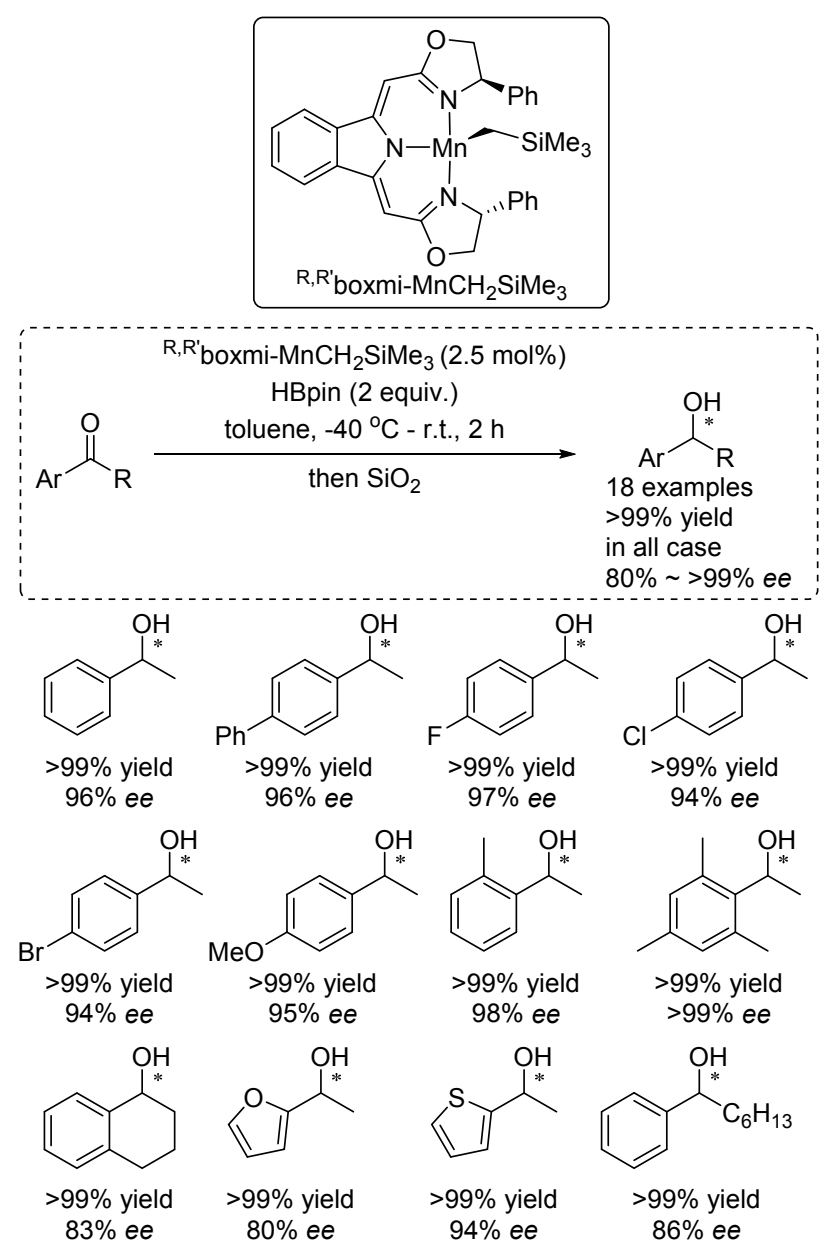

Scheme 5 Manganese-catalyzed enantioselective hydroboration of ketones by Gade

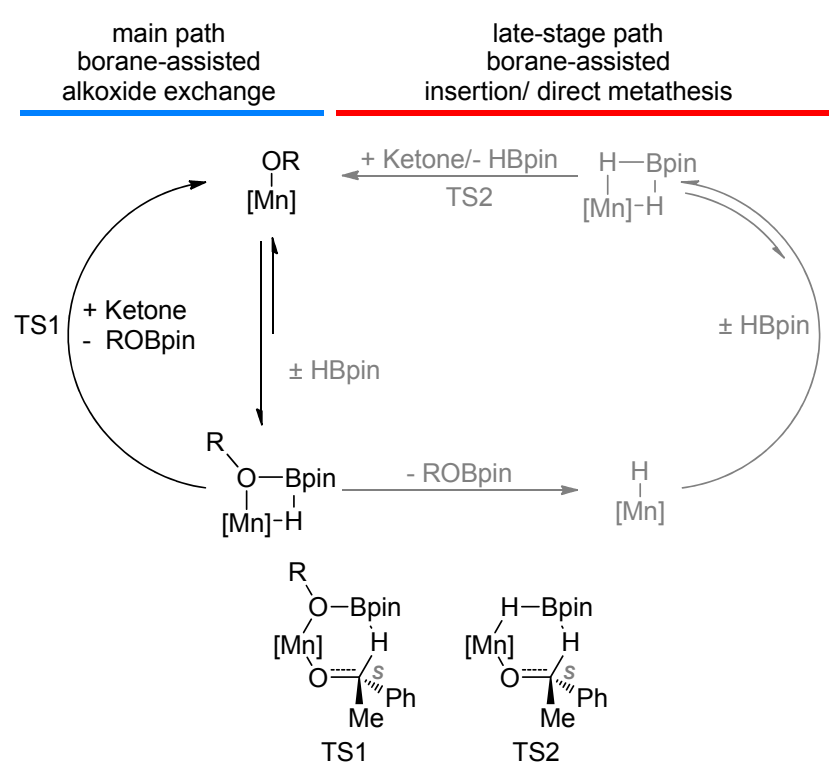

Scheme 6 Mechanistic investigation for Boxmi manganese alkyl complex catalyzed system by Gade

ketone, this cycle was the domination process during the early- and mid-stage of this reaction. The side reaction was 
a borane-assisted insertion/direct metathesis process and played a crucial role in late-stage due to its pseudo zeroth-order kinetics. According to DFT calculation, both processes favor the $S$-configuration of product.

This mechanistic investigation demonstrated that the HBpin could get involved in crucial catalytic process rather than just metathesis with metal alkoxide. It implied that the electro- and stereostructure of different boranes might play an important role for stereoselectivity and reactivity as they could be part of the key catalytic species and facilitate some transformations. It also highlights the mechanistic complexity of $3 \mathrm{~d}$ metal-mediated transformations.

In 2018, Gade's group ${ }^{[18]}$ developed a highly active enantioselective hydroboration system of functionalized ketones using boxmi iron alkyl with turnover frequency (TOF) up to $43500 \mathrm{~h}^{-1}$ at $-30{ }^{\circ} \mathrm{C}$ (Scheme 7). This protocol provides access to chiral halohydrines, oxaheterocycles and amino alcohols in good to excellent yield and ee.

$$
\text { (1) Cat. 1 (2.5 mol\%) }
$$

Scheme 7 Iron-catalyzed enantioselective hydroboration of functionalized ketones by Gade
Boxmi iron alkyl complex was also used in enantioselective hydroboration of imines with HBpin in 2020 by Gade's group ${ }^{[19]}$ to access $N$-alkyl $\alpha$-chiral amines (Scheme $8)$. Imines with substituents on meta- and para-position of aryl could be transformed with generally $>90 \% e e$. In contrast, substitution on ortho-position sharply affected both the yield and enantioselectivity.
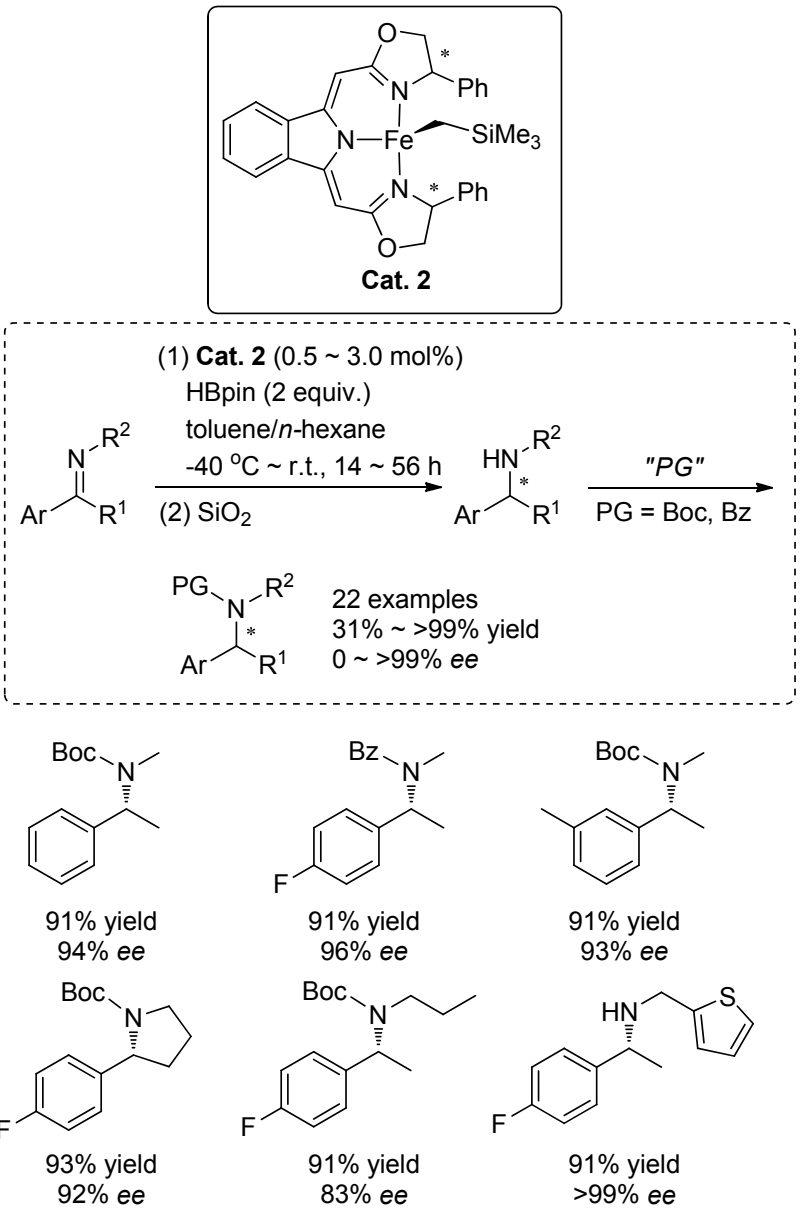

Scheme 8 Iron-catalyzed enantioselective hydroboration of imines by Gade

In 2020, Chen et al. ${ }^{[20]}$ reported an enantiodivergent hydroboration system of $\alpha$-keto amides with Hbpin (Scheme 9). A chiral oxido-vanadium complex were employed as catalyst to deliver chiral $\alpha$-hydroxyl amides. When HBpin or HBcat were used as reductant, the products were obtained with $R$ isomer (up to $99 \% e e$ ) or $S$ isomer (up to $90 \%$ ee) respectively.

\subsection{Main group elements catalysis}

Main group metals such like $\mathrm{Na}, \mathrm{Mg}$ and $\mathrm{Al}$ are among the most abundant metals in earth's crust and therefore reduce the cost for preparation of catalysts. The catalytic application of main group metals is developed rapidly in recent years.

A work of hydroboration of carbonyl with lithium complex was reported by Okuda et al. ${ }^{[21]}$ in 2016 that a well-defined lithium hydridotriphenyl borate bearing a 


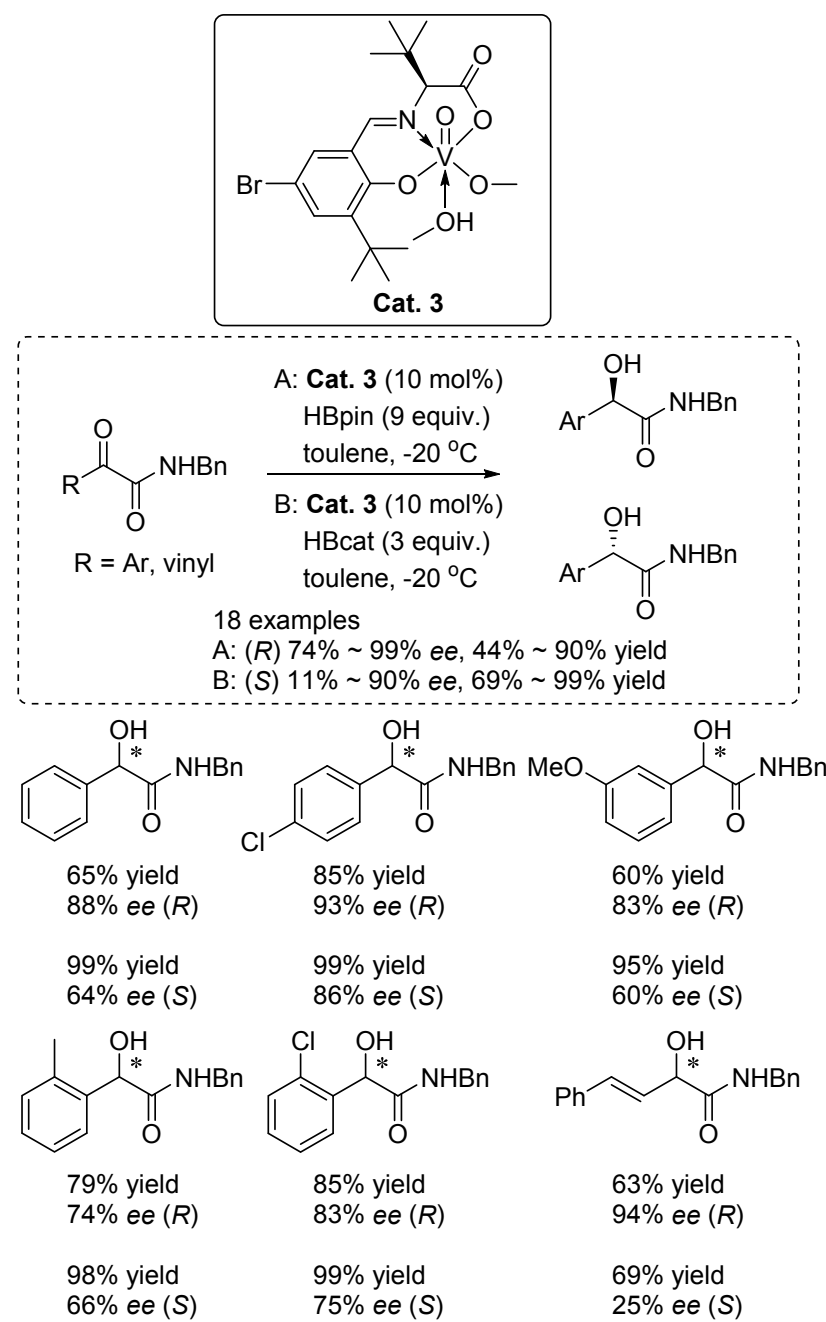

Scheme 9 Vanadium-catalyzed enantioselective hydroboration of $\alpha$-keto amides by Chen

chelating ligand (tris $\{2$-(dimethylamino)ethyl $\}$ amine) catalyzed carbonyl hydroboration with remarkable high TOF of $\geqslant 17 \mathrm{~s}^{-1}$. In 2020, Newman and Melen et al. ${ }^{[22]}$ reported an enantioselective hydroboration protocol with HBpin using lithium complex derived from chiral BINOL ligands (Scheme 10). 10 Examples of aryl alkyl methanols were obtained with moderate to excellent yield and 24\% 58\% ee utilizing $5 \mathrm{~mol} \%$ lithium diisopropylamide (LDA) with $10 \mathrm{~mol} \%$ BINOL derived ligand. Whether the lithium within the complex directly got involved in the catalytic process was not clear as no mechanism proposal was given.

The enantioselective CHB of ketones catalyzed by magnesium catalyst was reported by Rueping et al. ${ }^{[23]}$ in 2019 (Scheme 11). The reduction was performed at $-40{ }^{\circ} \mathrm{C}$ using BINOL-Mg complex as catalyst which was in situ generated from $7 \mathrm{~mol} \% \mathrm{MgBu}_{2}$ and $7.5 \mathrm{~mol} \%$ BINOL. The addition of $20 \mathrm{~mol} \%$ alkali salt $\mathrm{LiCl}$ slightly increased the enantioselectivity. The $e e$ values were generally good to excellent when alkyl aryl ketones, propargylic ketones and $\alpha, \beta$-unsaturated ketones were applied as substrates. Only 1,2-addition occurred during hydroboration of

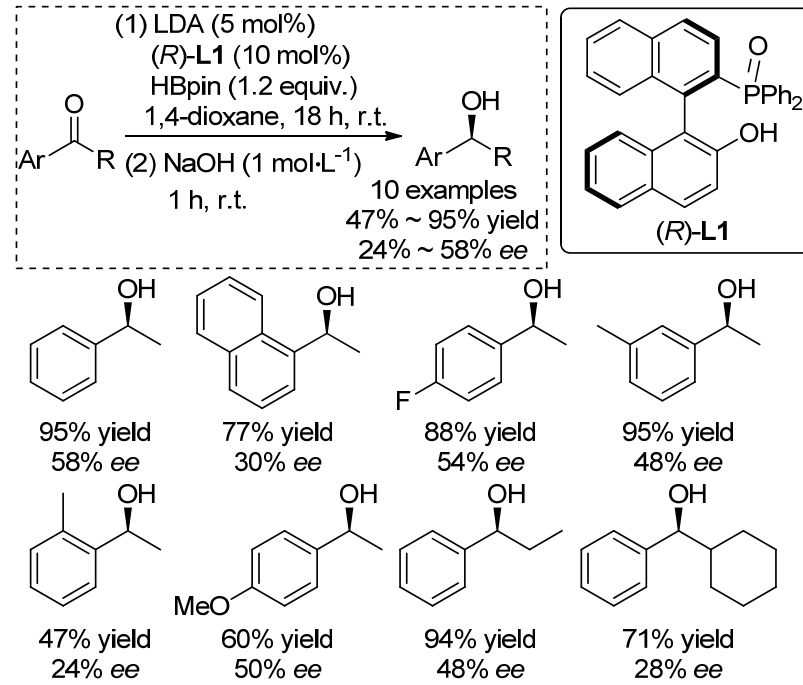

Scheme 10 Lithium-catalyzed enantioselective hydroboration of ketones by Newman and Melen
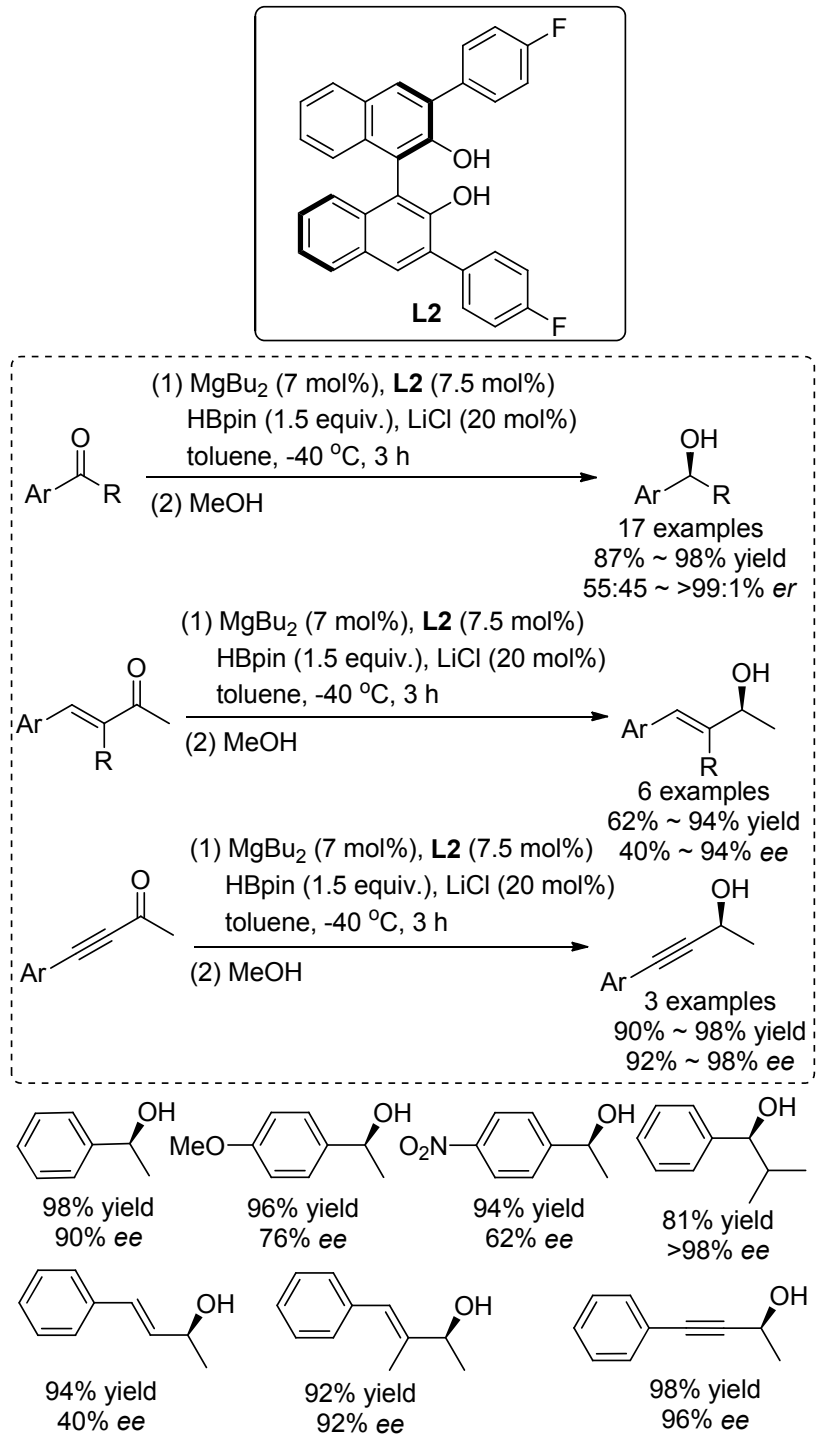

Scheme 11 Magnesium-catalyzed enantioselective hydroboration of ketones by Ruepin 
$\alpha, \beta$-unsaturated ketones in this catalytic system. Based on further control experiments, spectral data and DFT calculation, the author proposed a catalytic pathway in which BINOL could act as a non-innocent ligand. In contrast to the previously reported magnesium-catalyzed hydroboration system, this metal-ligand cooperative catalysis pathway doesn't involve $\mathrm{Mg}-\mathrm{H}$ species.

In 2020, Gade et al. ${ }^{[24]}$ reported another Mg-catalyzed enantioselective ketone reduction with HBpin (Scheme 12). The $5 \mathrm{~mol} \%$ precatalyst boxmi magnesium alkyl complex was used to deliver the methyl aryl ketones with 90\% 98\% ee. Hydroboration of cyclic alkyl aryl ketones, dialkyl ketone and alkynyl alkyl ketones resulted in lower $e e$. The absence of reactivity towards imines, epoxides, alkenes and esters were observed and thus demonstrated the chemical selectivity of this catalytic system. In situ NMR spectroscopy, X-ray diffraction study and DFT calculation established a zwitterionic structure as a critical catalytic motif rather than $\mathrm{Mg}-\mathrm{H}$.

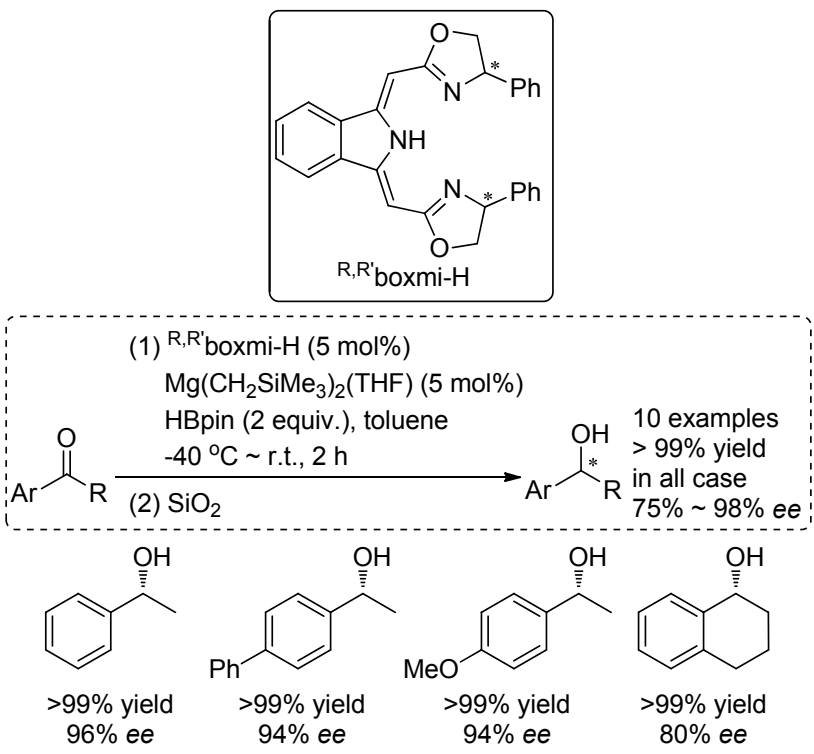

Scheme 12 Magnesium-catalyzed enantioselective hydroboration of ketones by Gade

An Al-based enantioselective hydroboration system of heteroaryl ketones with HBpin was developed by Rueping et $a .^{[25]}$ in 2019 (Scheme 13). A series of Al complex which generated in situ by reaction of $\mathrm{AlMe}_{3}$ with stoichiometric amount of commercially available chiral diols were used in this protocol to access a wide range of 2-pyridine and analogous heterocyclic ketones. This protocol was scaled up to $10 \mathrm{mmol}$ for 2 -acetly pyridine utilizing $0.2 \mathrm{~mol} \%$ catalyst loading without any loss in yield and enantioselectivity. It is worth noting that using HBcat instead of HBpin resulted in racemic product. Another commonly used hydroboration reagent 9 -BBN gave no product.

In 2017, enantioselective hydroboration of imines using chiral 1,3,2-diazaphospholene as catalyst with HBpin was achieved by Speed et al. (Scheme 14). ${ }^{[12]}$ A series of imines were transformed into amines with $10 \% \sim 76 \%$ ee.
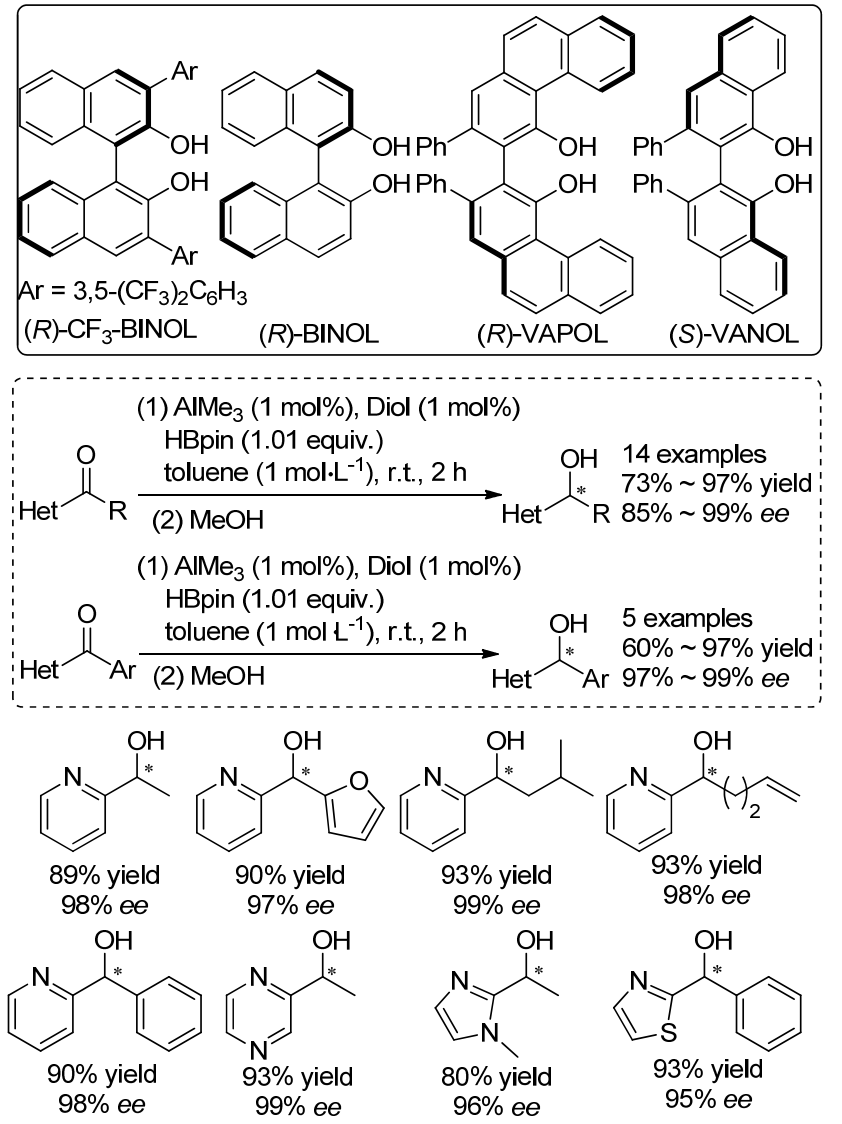

Scheme 13 Aluminum-catalyzed enantioselective hydroboration of ketones by Rueping
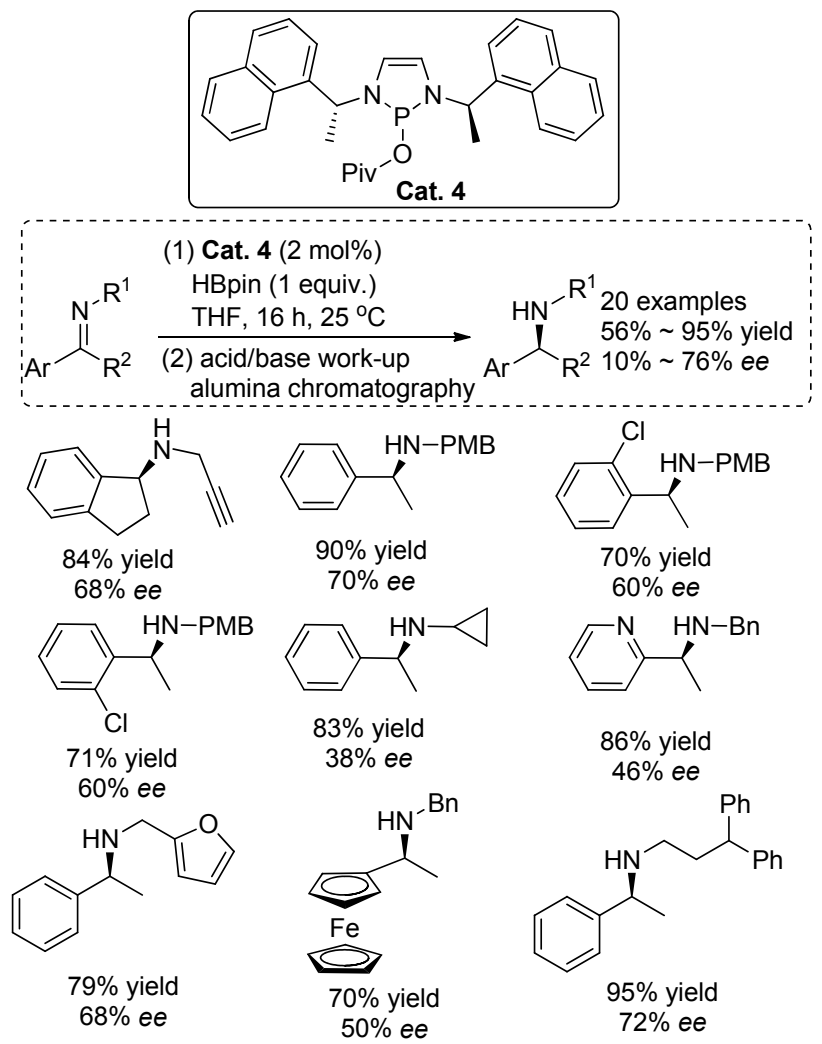

Scheme 14 Diazaphospholene-catalyzed enantioselective hydroboration of imines by Speed 
In 2019, Speed's group ${ }^{[26]}$ established enantioselective hydroboration system of cyclic imines with phosphenium catalyst (Scheme 15). Chiral 2-aryl or heteroaryl pyrrolidines were constructed with $76 \% \sim 94 \%$ ee using HBpin as reductant. replacement of $\mathrm{HBpin}$ with $\mathrm{HBcat}$ or $\mathrm{PhSiH}_{3}$ at $-35{ }^{\circ} \mathrm{C}$ resulted in lower ee.
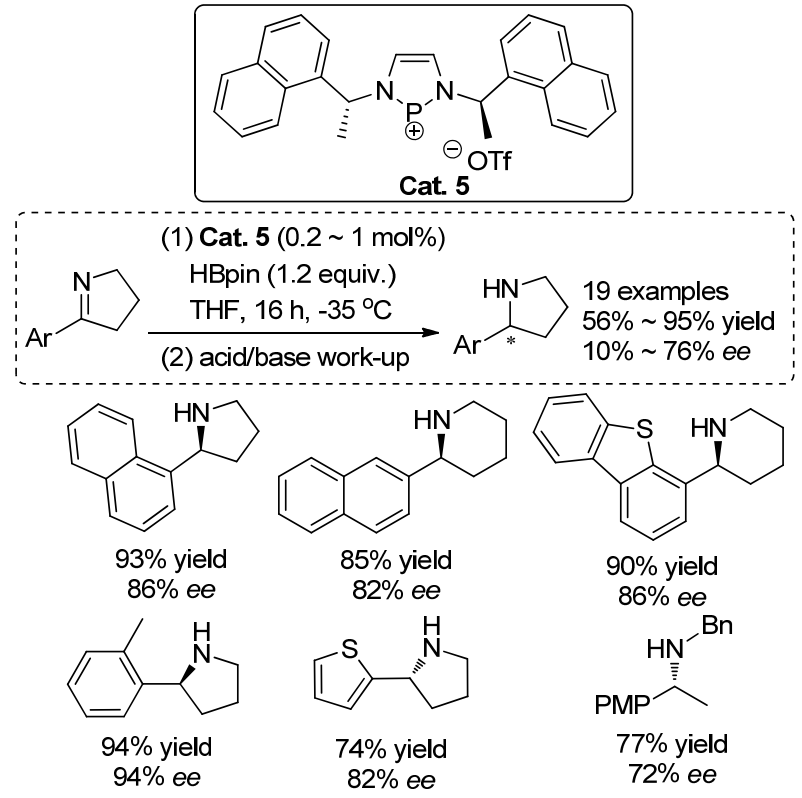

Scheme 15 Phosphenium ion-catalyzed enantioselective hydroboration of imines by Speed

Very recently, enantioselective reduction of 2-vinyl- substituted pyridines via 1,4-hydroboration and subsequent transfer hydrogenation was reported by Wang et al. ${ }^{[27]}$ (Scheme 16). As proposed mechanism, The intermediate $\mathrm{N}$-boryl imine cation was reducted by boron hydride which generated in situ by hydride transfer from HBpin to $\operatorname{RBAr}_{2}^{\mathrm{F}}$. A wide range of 2-vinyl-substituted piperidines were synthesized and the retained vinyl permitted further transformation to nature products and other useful heterocyclic compounds.

\subsection{Rare-earth metals catalysis}

In 2018, Zhao and Yao et al. ${ }^{[28]}$ reported the enantioselective hydroboration of ketones and $\alpha, \beta$-unsaturated ketones using rare-earth metals complex and HBpin (Scheme 17). Alkyl aryl ketones were reduced with $68 \% \sim 95 \%$ ee and $90 \% \sim 99 \%$ yield. Hydroboration of $\alpha, \beta$-unsaturated ketones via this protocol delivered 1,2-reduced products with $41 \% \sim 89 \%$ ee.

In 2020, Lu and Zhao et al. ${ }^{[29]}$ developed an enantioselective hydroboration system employing dinuclear rareearth metals complex with Trost ligands and HBpin (Scheme 18). Hydroboration of acetophenone derivatives resulted in $75 \% \sim>99 \%$ ee. In contrast, hydroboration of diaryl ketones and $\alpha, \beta$-unsaturated ketones led to lower enantioselectivity. A variety of functional groups such as nitro, ester, cyano, alkene and alkyne were all tolerated with good to excellent chemical selectivity.

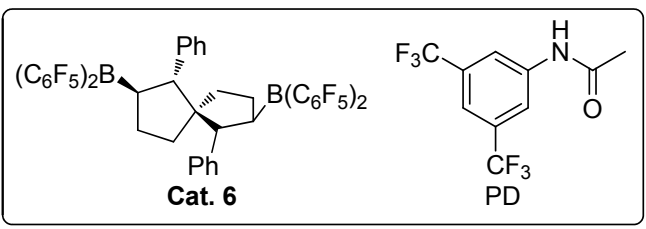

(1) Cat. 6 (1 $~ 5 \mathrm{~mol} \%)$

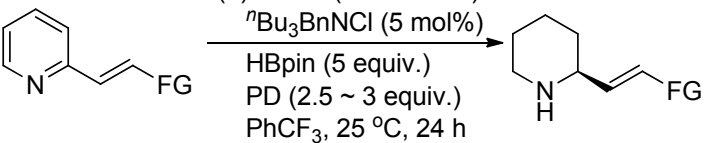

$\mathrm{PhCF}_{3}, 25^{\circ} \mathrm{C}, 24 \mathrm{~h}$

(2) hydrolysis

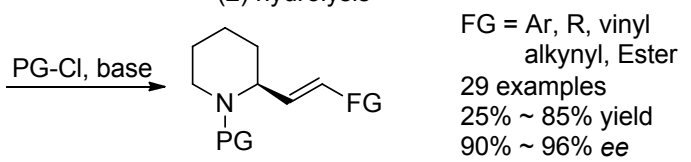

(1) Cat. 6 (2 $5 \mathrm{~mol} \%)$

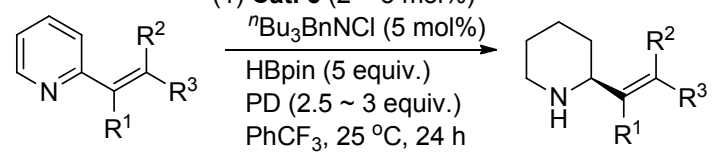

(2) hydrolysis

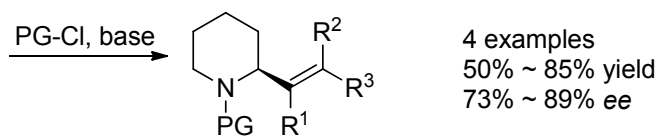

Scheme 16 Borane-catalyzed enantioselective reduction of 2vinyl-substituted pyridines by Wang
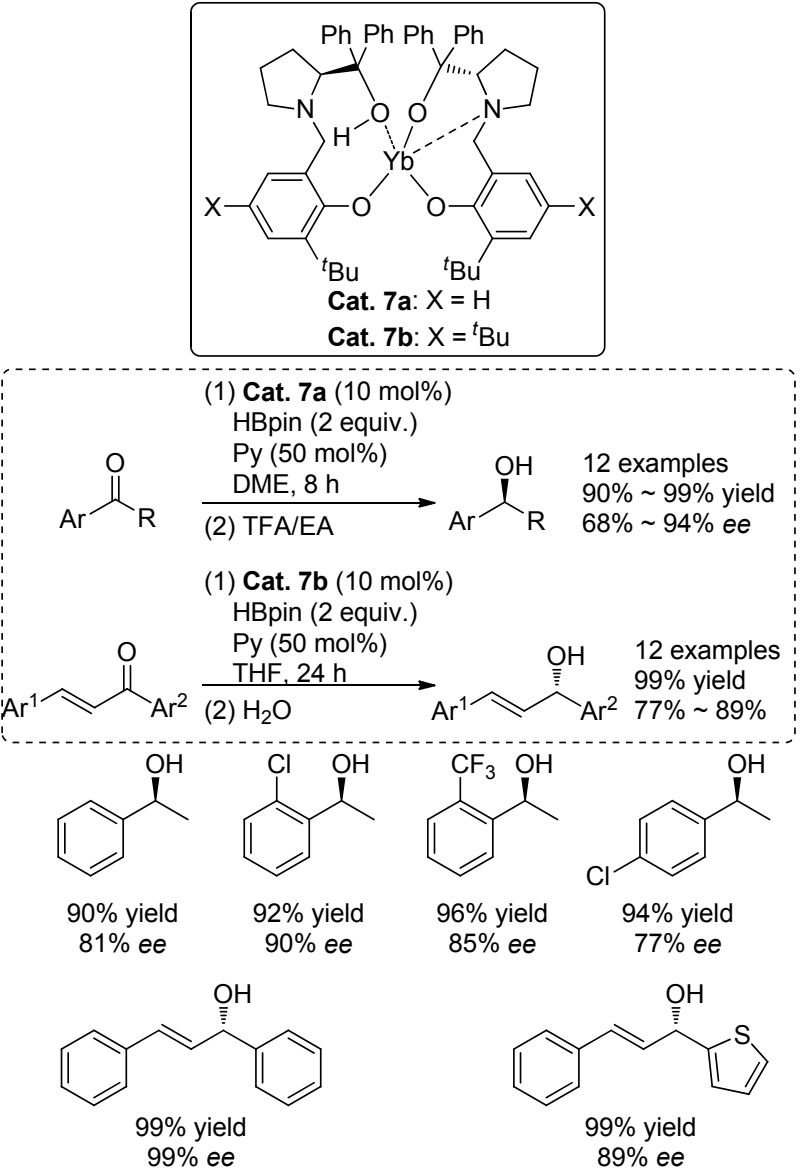

Scheme 17 Ytterbium-catalyzed enantioselective hydroboration of ketones by Zhao and Yao 

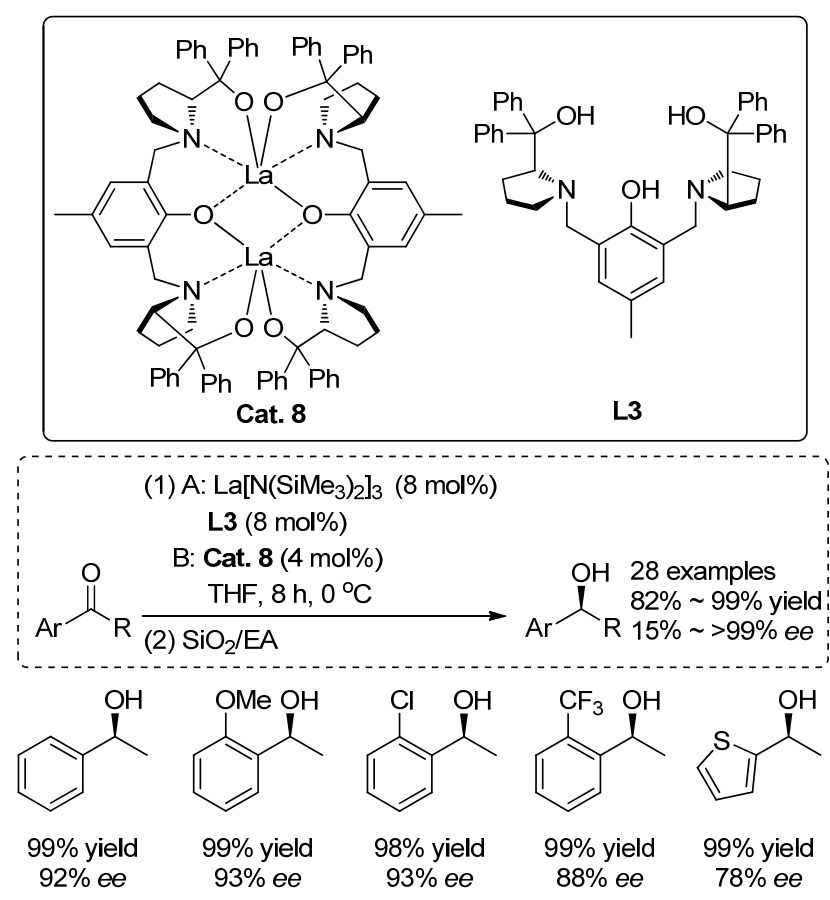

Scheme 18 Lanthanum-catalyzed enantioselective hydroboration of ketones by Lu and Zhao

\section{Conclusions}

In summary, the enantioselective hydroboration of ketones and imines using HBpin as a reductive reagent were reviewed. This field has been intensively developed with catalysts based on earth abundant transition metals, main group elements and rare-earth metals. These enantioselective catalytic methodologies provide a powerful method for the construction of a variety of secondary alcohols and amines with high ee. Due to the measurable ease of HBpin, the mechanistic research could be conducted with help of DFT model, kinetic experiments and others. The enantioselective hydroboration, as an alternative in the laboratory for traditional hydrogenation and transfer hydrogenation, is promising to apply to reductive amination and dynamic kinetic resolution of $\alpha$-substituted ketones.

For future, novel asymmetric reactions based on the various substrates would be explored using HBpin. So far, the highly enantioselective reduction of dialkyl ketones or imines is still a challenge. ${ }^{[30]}$ The development of novel chiral ligands is still highly desirable. Due to the success of the use of HBpin, the diversity of boranes may provide a wide platform for catalytic systems development and optimization. ${ }^{[31]}$ As the mechanistic studies are still limited, further deep investigation of mechanism will help to understand the details of hydroboration systems. The enantioselective catalytic hydroboration systems will provide useful models for other enantioselective reductive systems. ${ }^{[32]}$

\section{References}

[1] Marsden, S. Boronic Acids: Preparation and Applications in Or- ganic Synthesis, Medicine and Materials, Vols. 1 and 2, Ed.: Hall, D. G., Wiley-VCH, Weinheim, 2011.

[2] Chong, C. C.; Kinjo, R. ACS Catal. 2015, 5, 3238.

[3] Brown, H. C.; Schlesinger, H. I.; Burg, A. B. J. Am. Chem. Soc. 1939, 61, 673

[4] Wang, Z. In Comprehensive Organic Name Reactions and Reagents, Ed.: Wang, Z., John Wiley \& Sons, New Jersey, 2010, pp. $536 \sim 543$.

[5] Corey, E. J.; Helal, C. J. Angew. Chem., Int. Ed. 1998, 37, 1986.

[6] Tucker, C. E.; Davidson, J.; Knochel, P. J. Org. Chem. 1992, 57, 3482 .

[7] Shegavi, M. L.; Bose, S. K. Catal. Sci. Technol. 2019, 9, 3307.

[8] Koren-Selfridge, L.; Londino, H. N.; Vellucci, J. K.; Simmons, B. J.; Casey, C. P.; Clark, T. B. Organometallics 2009, 28, 2085.

[9] Query, I. P.; Squier, P. A.; Larson, E. M.; Isley, N. A.; Clark, T. B. J. Org. Chem. 2011, 76, 6452.

[10] Wu, Y.; Shan, C.; Ying, J.; Su, J.; Zhu, J.; Liu, L. L.; Zhao, Y. Green Chem. 2017, 19, 4169.

[11] Guo, J.; Chen, J.; Lu, Z. Chem. Commun. 2015, 51, 5725.

[12] Adams, M. R.; Tien, C.-H.; McDonald, R.; Speed, A. W. H. Angew. Chem., Int. Ed. 2017, 56, 16660.

[13] Noyori, R.; Ohkuma, T. Angew. Chem., Int. Ed., 2001, 40, 40.

[14] Liu, W.; Guo, J.; Xing, S.; Lu, Z. Org. Lett. 2020, 22, 2532.

[15] Chen, F.; Zhang, Y.; Yu, L.; Zhu, S. Angew. Chem., Int. Ed. 2017, 56, 2022.

[16] Vasilenko, V.; Blasius, C. K.; Wadepohl, H.; Gade, L. H. Angew. Chem., Int. Ed. 2017, 56, 8393.

[17] Vasilenko, V.; Blasius, C. K.; Gade, L. H. J. Am. Chem. Soc. 2018, 140, 9244.

[18] Blasius, C. K.; Vasilenko, V.; Gade, L. H. Angew. Chem., Int. Ed. 2018, 57, 10231.

[19] Blasius, C. K.; Heinrich, N. F.; Vasilenko, V. Gade, L. H. Angew. Chem., Int. Ed. 2020, 59, 15974.

[20] Agarwal, R.; Liao, Y.; Lin, D.-J.; Yang, Z.-X.; Lai, C.-F.; Chen, C.-T. Org. Chem. Front. 2020, 7, 2505.

[21] Mukherjee, D.; Osseili, H.; Spaniol, T. P.; Okuda, J. J. Am. Chem. Soc. 2016, 138, 10790

[22] Willcox, D.; Carden, J. L.; Ruddy, A. J.; Newman, P. D.; Melen, R. L. Dalton Trans. 2020, 49, 2417.

[23] Falconnet, A.; Magre, M.; Maity, B.; Cavallo, L.; Rueping, M. Angew. Chem., Int. Ed. 2019, 58, 17567.

[24] Vasilenko, V.; Blasius, C. K.; Wadepohl, H.; Gade, L. H. Chem. Commun. 2020, 56, 1203.

[25] Lebedev, Y.; Polishchuk, I.; Maity, B.; Guerreiro, M. D. V.; Cavallo, L.; Rueping, M. J. Am. Chem. Soc. 2019, 141, 19415.

[26] Lundrigan, T.; Welsh, E. N.; Hynes, T.; Tien, C.-H.; Adams, M. R.; Roy, K. R.; Robertson, K. N.; Speed, A. W. H. J. Am. Chem. Soc. 2019, 141, 14083 .

[27] Tian, J.-J.; Yang, Z.-Y.; Liang, X.-S.; Liu, N.; Hu, C.-Y.; Tu, X.-S.; Li, X.; Wang, X.-C. Angew. Chem., Int. Ed. 2020, 59, 18452.

[28] Song, P.; Lu, C.; Fei, Z.; Zhao, B.; Yao, Y. J. Org. Chem. 2018, 83, 6093.

[29] Sun, Y.; Lu, C.; Zhao, B.; Xue, M. J. Org. Chem. 2020, 85, 10504.

[30] Zhang, F.-H.; Zhang, F.-G.; Li, M.-L.; Xie, J.-H.; Zhou, Q.-L. Nat. Catal. 2020, 3, 621.

[31] For recent reactions with other boranes: (a) Taniguchi, T.; Curran, D. P. Angew. Chem., Int. Ed. 2014, 53, 13150 .

(b) Zhou, N.; Yuan, X.-A.; Zhao, Y.; Xie, J.; Zhu, C. Angew. Chem., Int. Ed. 2018, 57, 3990.

(c) Shimoi, M.; Watanabe, T.; Maeda, K.; Curran, D. P.; Taniguchi, T. Angew. Chem., Int. Ed. 2018, 57, 9485 .

(d) Yamamoto, K.; Mohara, Y.; Mutoh, Y.; Saito, S. J. Am. Chem. Soc. 2019, 141, 17042.

(e) Dai, W.; Geib, S. J.; Curran, D. P. J. Am. Chem. Soc. 2020, 142, 6261.

[32] For selected reviews: (a) Chen, J.; Lu, Z. Org. Chem. Front. 2018, $5,260$.

(b) Chen, J.; Guo, J.; Lu, Z. Chin. J. Chem. 2018, 36, 1075. 
(c) Cheng, Z.; Guo, J.; Lu, Z. Chem. Commun. 2020, 56, 2229.

(d) Li, Y. Y.; Cheng, Y. H.; Shan, C. H.; Zhang, J.; Xu, D. D.; Bai,

R. P.; Qu, L. B.; Lan, Y. Chin. J. Org. Chem. 2018, 38, 1885 (in Chinese).

(李园园, 程玉华, 单春晖, 张敬, 徐冬冬, 白若鹏, 屈凌波, 蓝
宇，有机化学， 2018，38，1885.)

(e) Sun, Y.; Guan, R.; Liu, Z. H.; Wang, Y. M. Chin. J. Org. Chem. 2020, 40, 651 (in Chinese).

(孙越, 关瑞, 刘兆洪, 王也铭, 有机化学, 2020, 40, 651.)

(Sun, H.) 